Military Technical College Kobry Elkobbah, Cairo, Egypt.

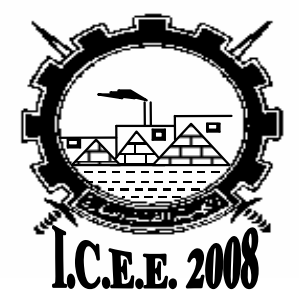

$4^{\text {th }}$ International Conference On Chemical \& Environmental Engineering

27-29 May 2008

\title{
PARA-XYLENE MAXIMIZATION-PART VII ALKYLATION OF TOLUENE WITH METHANOL AND DIFFUSION EFFECTS ON DIFFERENTLY HYDROFLUORINATED H-ZSM-5 CATALYSTS
}

\author{
ABOUL-GHEIT*, A. K., HANAFI, S. A., \\ GHONEIM, S. A.* ABOUL-ENEIN, A.A.
}

\begin{abstract}
There is a considerable industrial demand for para-xylene because of its importance as raw material for the manufacture of terphthalic acid, which a major component in the production of polyester fibers, polyethylene terephthalate resins, vitamins and other pharmaceuticals. In this work, H-ZSM-5 zeolite was hydrofluorinated to modify its acid sites number and strength. This zeolite, before and after HF treatment was tested as a catalyst for the alkylation of toluene with methanol at reaction temperatures of $300-500^{\circ} \mathrm{C}$, molar ratio of methanol to toluene of 2.5 and liquid hourly space velocity of $2.6 \mathrm{v} / \mathrm{v} / \mathrm{h}$. HF acid concentrations between 1.0 and $4.0 \mathrm{wt} \%$ were also examined. The reaction selectivity for para-xylene production has been found to reach an optimum at an HF concentration of $3.0 \mathrm{wt} \%$. The catalysts were characterized by temperature programmed desorption (TPD) of ammonia for acid sites distribution analysis. The BET surface area and pore volume for each catalyst were also estimated. Higher concentrations of HF have been found to cause leaching of the structural aluminium of the zeolite, causing fluoro-alumino debris that results in blocking of the channels of this zeolite and giving higher values of Thiele modulus $\left(\Phi_{\mathrm{L}}\right)$ and hence lower values of effectiveness factor $(\eta)$. The simple kinetic evaluation of the reaction rate constant, $\mathrm{k}$, and apparent activation energy were carried out.
\end{abstract}

\section{KEY WORDS:}

$\mathrm{H}-\mathrm{ZSM}-5$, alkylation, toluene, methanol, dealumination, hydrofluorination, and diffusion.

\footnotetext{
Egyptian Petroleum Research Institute, P.O. Box 9540, Nasr City, Cairo 11787, Egypt Corresponding author salwaghoneim70@yahoo.co
} 


\section{NOMENCLATURE}

\begin{tabular}{|c|c|}
\hline Cs & Surface concentration, $\mathrm{gm} \mathrm{mol} / \mathrm{cm}^{3}$ \\
\hline$D_{12 \text { eff }}$ & Effective binary diffusion coefficient, $\mathrm{cm}^{2} \mathrm{~s}^{-1}$ \\
\hline$D_{\text {eff }}$ & Effective diffusion coefficient, $\mathrm{cm}^{2} \mathrm{~s}^{-1}$ \\
\hline$D_{\text {keff }}$ & Effective Knudsen diffusion coefficient, $\mathrm{cm}^{2} \mathrm{~s}^{-1}$ \\
\hline DSC & Differential scanning calorimetry \\
\hline Ea & Apparent activation energy, $\mathrm{J} \mathrm{mol}^{-1}$ \\
\hline eu & Entropy unit, cal $\mathrm{mol}^{-1} \mathrm{~K}^{-1}$ \\
\hline $\mathrm{F}$ & Carrier gas flow rate $\left(\mathrm{cm}^{3} \mathrm{~s}^{-1}\right.$ at STP). \\
\hline $\mathrm{H}$ & Plank's constant \\
\hline K & The true rate constant \\
\hline $\mathrm{K}$ & The adsorption equilibrium constant \\
\hline $\mathrm{k}_{\mathrm{b}}$ & Boltzmann's constant \\
\hline kK & Apparent reaction rate constant \\
\hline $\mathrm{k}_{\mathrm{v}}$ & Intrinsic first order reaction rate constant, $\mathrm{sec}^{-1}$ \\
\hline $\mathrm{L}$ & The volume of a catalyst /external surface area of particle, $\mathrm{cm}$ \\
\hline M & The order of reaction \\
\hline $\mathrm{R}$ & The gas constant $=8.3144 \mathrm{~J} / \mathrm{g} \mathrm{mol} \mathrm{K}{ }^{\circ}$ \\
\hline $\mathrm{T}$ & Absolute reaction temperature, $\mathrm{K}^{\circ}$ \\
\hline TPD & Temperature programmed desorption \\
\hline W & Weight of catalyst, $\mathrm{g}$. \\
\hline WHSV & Weight hourly space velocity, $\mathrm{h}^{-1}$ \\
\hline $\mathrm{x}$ & Mole fraction converted \\
\hline$\Delta \mathrm{H}^{*}$ & Activation enthalpy, $\mathrm{J} \mathrm{mol}^{-1}$ \\
\hline$\Delta \mathrm{H}_{\text {des }}$ & Enthalpy of $\mathrm{NH}_{3}$ desorption, $\mathrm{Jg}^{-1}$ \\
\hline$\Delta S^{*}$ & Entropy of activation \\
\hline$\Phi_{\mathrm{L}}$ & Thiele diffusion modulus for general case, dimensionless \\
\hline
\end{tabular}




\section{INTRODUCTION}

There is a considerable industrial demand for para-xylene because of its importance as raw material for the manufacture of terphthalic acid, which a major component in the production of polyester fiber, polyethylene terephthalate resins, vitamins and other pharmaceuticals. Methylation of toluene was carried out over several acidic zeolites such as ZSM-5, mordenite, SAPO-11, and Y zeolites [1-9]. As a result, there were great difference in the catalytic activity and selectivity among these zeolites. Moreover, by means of modifying acidity and pore structure of ZSM-5, some coreactions could be restricted effectively, and the selectivity of methylation of toluene to para-xylene is improved as well $[10,11]$.

The modification of metal-oxide catalysts by fluoride treatment has been commonly used to promote acid catalyzed reactions, particularly for alumina-based catalysts [12]. The fluoride ion is thought to replace surface oxide or hydroxide groups, and because fluorine is very electronegative, it polarizes the framework, thereby increasing the acidity and reactivity of the surface. Because zeolites are inherently more acidic than are aluminas, much less work has appeared in the literature on the effect of fluorine treatment on zeolites. However, it has been pointed out that fluorine treatment by various means increases both the activity and stability of some important siliceous zeolites such as ZSM-5. Lok et al. [13,] found a high activity for nbutane cracking on ZSM-5 when mild fluorination of the catalyst was carried out, whereas low activity was observed after severe fluorine treatment. Becker and Kowalak [14] reported the results of a modification of $\mathrm{H}$-mordenite with ammonium fluoride solutions and gaseous $\mathrm{CHF}_{3}$. Also, it has been reported in the patent literature that the high-silica pentasil zeolites exhibit enhanced Brönsted acidity and therefore improved catalytic activity after treatment with various fluorine-containing compounds $[15,16]$. In a previous study, the effect of HF treatment on the acidity and catalytic activity of fluoride-pretreated mordenite were reported [17]. It was found that aqueous HF treatment of $\mathrm{H}$-mordenite caused aluminum, at mild conditions, and silicon, at more severe conditions, to be leached from the zeolite structure. Surface areas were significantly decreased. Infrared spectra indicated that the number, of strong Lewis acid sites and weak Brönsted acid sites increased after mild fluoride treatment.

In this paper, H-ZSM-5 zeolite was modified by aqueous solutions of HF containing various HF concentrations ( 1 up to $4 \mathrm{wt} \% \mathrm{HF}$ ). The fluorinated catalysts were examined to study their activities for the alkylation of toluene with methanol for maximizing the production of para-xylene in a fixed-bed continuous flow reactor using hydrogen as a carrier and reaction temperatures between $300^{\circ} \mathrm{C}$ and $500^{\circ} \mathrm{C}$.

\section{EXPERIMENTAL}

\section{Catalysts Preparation}

The sodium ZSM-5 zeolite, supplied by "Sud-Chemie AG" in the form of powder, was transformed to the ammonium form by cation exchange using molar solution of $\mathrm{NH}_{4} \mathrm{NO}_{3}$ five times; each for $8 \mathrm{~h}$, using a fresh solution of $\mathrm{NH}_{4} \mathrm{NO}_{3}$ at $70^{\circ} \mathrm{C}$ under 
reflux and stirring. The zeolite was then separated from the solution, washed six times with distilled water and dried overnight at $110^{\circ} \mathrm{C}$. The quantity of zeolite thus obtained was calcined at $530^{\circ} \mathrm{C}$ for $4 \mathrm{~h}$ to transform it to the $\mathrm{H}$-form. The quantity of HF (40\%, A.R. grade product of "Riedel de Haen") required for preparation a catalysts containing 1,2, 3 and $4 \% \mathrm{HF}$ was dissolved in distilled water sufficient for covering the zeolite to be fluorinated. The zeolite in HF-containing solution was left at room temperature overnight and then dried overnight at $120^{\circ} \mathrm{C}$. The catalyst was then calcinated at $450^{\circ} \mathrm{C}$ for $4 \mathrm{~h}$.

\section{Alkylation Procedure and Apparatus}

The catalytic runs were carried out at atmospheric pressure in a fixed bed down flow reactor. The catalyst was used as powder ( $1 \mathrm{~g}$ for each run) which was diluted with inert porcelain particles. A mixture of methanol and toluene (molar ratio 2.5-1) was fed into the reactor via electronic dosing pump. The product effluent was passed into a cooling condenser at $3^{\circ} \mathrm{C}$, then to a receiver where the liquid product was collected and gas chromatographically analyzed using a column packed with $5 \%$ Bentone 34 and $5 \%$ diisodecylphthalate on Chromosorb-W.

The alkylation runs were carried out at reaction temperatures between $300^{\circ} \mathrm{C}$ and $500^{\circ} \mathrm{C}$, a liquid hourly space velocity of $2.6 \mathrm{~h}^{-1}$ and a continuous hydrogen flow of 20 $\mathrm{cm}^{3} \mathrm{~min}^{-1}$.

\section{Temperature Programmed Desorption of Ammonia (TPDA)}

The procedure of Aboul-Gheit et al. $[18,19]$ using differential scanning calorimetry (DSC) for detecting desorption of presorbed ammonia from the catalysts via the programmed temperature increase in an inert atmosphere was used. Primarily ammonia was adsorbed on the acid sites of the catalyst after previous heating in air flow at $500^{\circ} \mathrm{C}$ for $3 \mathrm{~h}$ in a silica tube furnace. After cooling to $50^{\circ} \mathrm{C}$, ammonia gas flow of $50 \mathrm{~cm}^{3} \mathrm{~min}^{-1}$ was applied over the evacuated catalyst. The DSC measurements were carried out in a DSC-30 unit of the TA-3000 Mettler system, using standard Al crucibles in a flow of $50 \mathrm{~cm}^{3} \mathrm{~min}^{-1}$ of oxygen-free nitrogen purge gas. The DSC conditions were: temperature: $50-600^{\circ} \mathrm{C}$, heating rate: $5 \mathrm{~K} \mathrm{~min}^{-1}$, full scale range: 30 $\mathrm{mW}$, plot: $10 \mathrm{~cm}$, sample mass: $10 \mathrm{gm}$.

The desorption enthalpy obtained corresponds to the acid sites density, whereas the DSC peak temperature was used to compare the acid site strength. Two DSC endotherms appear in each thermogram, the higher-temperature-one corresponds to the strong acid sites responsible for catalyzing the reaction under study (Table 1).

\section{Surface Area}

BET total surface area and total pore volume were determined by nitrogen adsorption/desorption, using a Quatachrome NovaWin2 apparatus (Table 2). 


\section{RESULTS AND DISCUSSION}

\section{Toluene Conversion}

Fig. 1 shows that toluene conversion, using the fluorinated $\mathrm{H}-\mathrm{ZSM}-5$ catalysts doped with $1,2,3$, and $4 \% \mathrm{HF}$ is higher than that using the untreated $\mathrm{H}-\mathrm{ZSM}-5$ catalyst at reaction temperatures of $300-500^{\circ} \mathrm{C}$. This may be attributed to enhancing of the surface acidity of the H-ZSM-5 zeolite (Table 1) by incorporation of fluoride ions in relatively low concentrations. Doping of the untreated $\mathrm{H}-\mathrm{ZSM}-5$ zeolite $\left(\Delta \mathrm{H}_{\mathrm{d}}=105.1\right.$ $\mathrm{Jg}^{-1}$ ) with 1.0 then with $2.0 \% \mathrm{HF}$ increases the $\Delta \mathrm{H}_{\mathrm{d}}$ to 106.0 and $107.5 \mathrm{Jg}^{-1}$, respectively; however, a further increase of doping the zeolite with HF to 3.0 and $4.0 \%$, the $\Delta H_{d}$ values decrease to 101.9 and $98.3 \mathrm{Jg}^{-1}$, respectively. Since these ammonia desorption values are related to or rather correspond to the number of acid sites, this reflects that the number of acid strong sites increase slowly to reach a maximum via doping with $2.0 \% \mathrm{HF}$; beyond which the number decreases. However, the strength of these acid sites increase gradually as evident through correlating the desorption peak values, such that the lowest acid strength is acquired by the untreated zeolite, whereas the highest strength is acquired by the $4.0 \% \mathrm{HF}$-treated $\mathrm{H}$ ZSM-5 catalyst. ZSM-5 zeolite, when doped with fluorine species, the surface acidity is enhanced because of: (i) the formation of new Brönsted acid sites; (ii) and the strengthening of some acid sites of the parent zeolite [20]. It is evident that doping $2 \% \mathrm{HF}$ in the $\mathrm{H}-\mathrm{ZSM}-5$ zeolite gives the highest toluene conversion at temperatures above $350^{\circ} \mathrm{C}$ (Fig. 1). Using all the catalysts under study, except for the $4 \% \mathrm{HF}$ doped catalyst; the conversion of toluene behaves in a regime of passing to a maximum followed by a decline of conversion with a further increase of temperature. Only using the $4 \% \mathrm{HF}$ doped catalyst, the activity of the catalyst increases continually as a function of reaction temperature. Even though, the activity (toluene conversion) exceeds those of other catalysts only during the low temperatures $\left(300-350^{\circ} \mathrm{C}\right)$.

\section{Total Xylenes in Product}

Fig. 2 shows the total xylenes production on the hydrofluorinated $\mathrm{H}-\mathrm{ZSM}-5$ catalysts as a function of reaction temperature. In the lower temperature range $\left(300-350^{\circ} \mathrm{C}\right)$, the yield of total xylenes is highest on the $4 \% \mathrm{HF}$ doped catalyst, whereas at temperatures between $400-450^{\circ} \mathrm{C}$, the $1 \% \mathrm{HF}$ doped catalyst exhibits highest activity. However, beyond $450^{\circ} \mathrm{C}$, the activity of this catalyst drops to be the lowest among the $\mathrm{HF}$ treated catalysts at $500^{\circ} \mathrm{C}$. At temperatures between 400 and $450^{\circ} \mathrm{C}$, the production of xylenes is in the order:

H-ZSM-5 (1\%HF) > H-ZSM-5 (2\%HF) > H-ZSM-5 $(3 \% \mathrm{HF})$

which accords with the increased acid sites strength (Table 1). However, the continually increasing behavior of the xylenes production on the H-ZSM-5 (4\%HF) catalyst can be attributed to the presence of relatively larger amount of pores falling in the mesoporous range due to more efficient leaching of $\mathrm{Al}$ and $\mathrm{Si}$ with HF from the framework of the zeolite. The produced larger pores by the $4 \% \mathrm{HF}$ treatment facilitate diffusion of the relatively large molecules of the xylenes. 


\section{Para-Xylene Selectivity}

Since the production of para-xylene is the principal target of the present work, the comparison given in Fig. 3 should be of prime importance. Obviously, the $3 \% \mathrm{HF}$ doped $\mathrm{H}-\mathrm{ZSM}-5$ catalyst is the catalyst of choice by virtue of its superiority in producing para-xylene at all reaction temperatures. Using this catalyst, para-xylene comprises $40.8 \%$ at $300^{\circ} \mathrm{C}$ then decreases continually with increasing reaction temperature to reach $34.4 \%$ at $500^{\circ} \mathrm{C}$. All these values exceed the thermodynamic equilibrium values which are around $23.0 \%$ at the operating temperatures in this study [21]. These findings prove that the H-ZSM-5 (3\%HF) catalyst acquires the optimum para-selectivity among the current catalysts.

The arrangement of the selectivities of the catalysts under study for para-xylene production at the whole range of temperature investigated $\left(300-500^{\circ} \mathrm{C}\right)$ is shown in Fig. 3 to be in the following order:

H-ZSM-5 (3\%HF) > H-ZSM-5 (2\%HF) > H-ZSM-5 (1\%HF) > untreated H-ZSM-5.

However, the H-ZSM5 (4\%HF) catalyst does not behave as normally parallel to the selectivities of the other catalysts. It shows a relatively higher para-selectivity during the lower temperature range and a relatively lower selectivity during the higher temperature range. This behavior of $4 \% \mathrm{HF}$ treated catalyst can be attributed to (1) a higher acidity which is effective in the lower temperature range, and (2) larger amorphous debris deposited in the channels which is effective in the higher temperature range. The production of para-xylene increases with the quantity of HF doped on the zeolite up to $3 \% \mathrm{HF}$, beyond which the para-xylene selectivity declines. The increase of surface area during the $1 \%$ and $2 \% \mathrm{HF}$ treatments can be attributed to dissolution of the originally present hydroxy-alumino-debris on the surface and pores of the zeolite which was formed during the synthesis of the zeolite [22]. The treatment with $3 \% \mathrm{HF}$ seems to have adjusted the surface properties to attain the optimum surface and pore structure that provides the optimum selectivity for paraxylene production. This finding may indicate that it is not the magnitude of surface area or pore volume of the zeolite that controls the para-selectivity but it can be said that it is the position of the debris formed during the HF treatment in the host zeolite that controls the catalytic behavior.

In Fig. 4, the para-xylenes selectivity at 300 and $500^{\circ} \mathrm{C}$ is plotted as a function of $\mathrm{HF}$ concentration. At both temperatures, the increase of HF concentration up to $3 \% \mathrm{HF}$ is found to improve the para-xylene selectivity to attain a maximum, beyond which the increase of HF concentration to $4 \%$ results in para selectivity decrease.

\section{Trimethylbenzenes in Product (TMBs)}

Fig. 5 shows that the untreated zeolite catalyst exhibits maximum production of TMBs between 400 and $450^{\circ} \mathrm{C}$. Using the $1 \%$ and $2 \% \mathrm{HF}$ containing catalysts, TMBs are almost the same from the beginning at $300 \mathrm{oC}$ till at $450 \mathrm{oC}$ then deviate with increasing temperature to $500^{\circ} \mathrm{C}$, such that on the $1 \% \mathrm{HF}$ catalyst, TMBs comprise $10.3 \%$ while they comprise $19.1 \%$ on the $2 \% \mathrm{HF}$ treated catalyst. Evidently, HF concentration higher than $2 \%$ is inhibiting TMBs production. Fig. 5 shows that the 3 
and 4\% HF treatments give lower TMBs. This effect can be attributed to decreasing the surface area as a function of increasing the acid concentration. Using the 1, 2, 3 and $4 \% \mathrm{HF}$ treated zeolite catalysts, the surface areas are $370.1,371.0,324.3$ and $311.6 \mathrm{~m}^{2} \mathrm{~g}^{-1}$, respectively, whereas, the untreated zeolite acquires an area of 345.4 $\mathrm{m}^{2} \mathrm{~g}^{-1}$ (Table 2), these values appear in accordance with the production of TMBs.

\section{Gas Production:}

The production of gases via hydrocracking normally increases as a function of reaction temperature. It is evident that these gases increase significantly with the first treatment using $1 \% \mathrm{HF}$ and continues increasing with $2 \% \mathrm{HF}$ treatment. Increasing the concentration of $\mathrm{HF}$ to $3 \%$, results in significant drop of the hydrocracked gases at all temperatures, then gets some more decrease with a further increase of HF concentration to $4 \%$. Correlation of the production of gases (Fig. 6) with the surface area and pore volume (Table 2 ) indicates their mutual dependence.

\section{Kinetics of Toluene Alkylation with Methanol using the Hydrofluorinated H-ZSM-5 Catalysts:}

\section{Reaction rate constant:}

From the reaction data of total xylene in Fig. 3, the apparent reaction rate constant, $\mathrm{kK}$ has been calculated according to the simple batch equation:

$$
k K=\frac{F}{W} \cdot \ln (1 / 1-x)=\frac{W H S V}{3600} \ln \frac{1}{1-x}
$$

\section{Thermodynamic parameters}

The activation energy $\left(E_{a}\right)$ for the alkylation reaction using the current catalysts has been calculated using the traditionally accepted Arrhenius equation and kK values obtained according to equation (1). According to the absolute reaction rate theory, the reaction rate constant is correlated to an activation enthalpy $\left(\Delta H^{*}\right)$ and an activation entropy $\left(\Delta S^{*}\right)$ as in equation (2):

$$
\text { (2) } k_{v}=\frac{k_{b} T}{h} e^{-\Delta H^{*} / R T} \cdot e^{\Delta S^{*} / R}
$$

The apparent activation energy, $E_{a}$, is calculated via applying the Arrhenius plot (Fig. 7) of In k vs. 1/T, where $\mathrm{k}$ is the reaction rate constant and $\mathrm{T}$ is the absolute reaction temperature. The $E_{a}$ values calculated accordingly are tabulated in Table 3 . Indeed, the values in Table 3 are relatively low, indicating that the effect of temperature in accelerating the current reaction is of a modest concern. However, evidently, the highest $E_{a}$ value is obtained using the $1 \% \mathrm{HF} / \mathrm{H}-\mathrm{ZSM}-5$ catalyst, indicating that such low concentration of HF results in the highest activation with temperature during the 
low temperature range $\left(300-400^{\circ} \mathrm{C}\right)$. The $2 \% \mathrm{HF} / \mathrm{H}-\mathrm{ZSM}-5$ catalyst shows slight lowering of $E_{a}$ and such decrease with increasing HF concentration continues also using the $3 \% \mathrm{HF} / \mathrm{H}-\mathrm{ZSM}-5$ catalyst. The difference between the catalytic response of these three catalysts towards HF doping is very slight but exhibiting a decreasing trend. This indicates that the increase of amorphous debris formed is via leaching Al and $\mathrm{Si}$ in the zeolite composition slightly effective on the physical structure of the porous system of these catalysts. On the other hand, the $3 \% \mathrm{HF} / \mathrm{H}-\mathrm{ZSM}-5$ catalyst exhibits a more significant physical change of the pores and cavities of the supporting H-ZSM-5 zeolite, i.e., due to significant formation and deposition of the amorphous debris on the catalytic surface.

The $\Delta S^{*}$ (activation entropy) values calculated for toluene conversion using the current catalysts show insignificantly different values. In general, these values reflect that this reaction encounters significant molecular restriction during transforming to the activated state. The mode of reaction on the active sites located on the catalytic surface of the four current catalysts is almost indifferent although the activities are not indifferent.

\section{Diffusion Effects Resulting Via Hydrofluorination of H-ZSM-5 Catalysts:}

The effect of hydrofluorination on H-ZSM-5 zeolite as a catalyst has been investigated via inclusion of HF acid in increasing dosage from $1 \%$ up to $4 \%$ in zeolite. The magnitude of diffusion restriction in these catalysts is expressed in a term abbreviated as $\Phi_{\mathrm{L}}$.

To correlate quantitatively the difference in diffusion resistance in a series of catalysts, the dimensionless parameter Thiele modulus $\left(\Phi_{\mathrm{L}}\right)$ can be considered the most appropriate approach. This modulus is calculated by iteration on the reaction rate constant $k_{\mathrm{v}}$ applying equations 3 and 4 .

$\Phi_{L}=L\left(k_{v} C_{s}^{m-1} / D_{\text {eff }}\right)^{1 / 2}$

Detailed calculation of the Thiele modulus is given by Satterfield and Sherwood [23]. The effective binary diffusivity $\left(D_{12}\right)$ for methanol and toluene, the Knudsen diffusivity $\left(D_{k}\right)$ and the effective diffusivity $\left(D_{\text {eff }}\right)$ are correlated together according to:

$1 / D_{\text {eff }}=1 / D_{12, \text { eff }}+1 / D_{K, \text { eff }}$

Fig. 8 shows that $\Phi_{\mathrm{L}}$ increases consecutively with increasing the fluoride content in the $\mathrm{H}-\mathrm{ZSM}-5$ zeolite under study. The $\Phi_{\mathrm{L}}$ values calculated for the untreated zeolite is also included for comparison. It is evident that $1 \% \mathrm{HF}$ inclusion in $\mathrm{H}-\mathrm{ZSM}-5$ increases the $\Phi_{\mathrm{L}}$ value from 8.98 at $300^{\circ} \mathrm{C}$ to 14.85 at $450^{\circ} \mathrm{C}$. This $\Phi_{\mathrm{L}}$ variation as a function of temperature is relatively high compared to the extent of $\Phi_{\mathrm{L}}$ variation resulting on the untreated $\mathrm{H}-\mathrm{ZSM}-5$ catalyst. An increase of $\mathrm{HF}$ incorporation to $2 \%$ increases the $\Phi_{\mathrm{L}}$ to 10.92 at $300^{\circ} \mathrm{C} 17.08$ at $450^{\circ} \mathrm{C}$. Also, an increase of HF up to $3 \%$ rises $\Phi_{\mathrm{L}}$ to 12.76 at $300^{\circ} \mathrm{C}$ and 18.19 at $450^{\circ} \mathrm{C}$. Finally, the increase of $\mathrm{HF}$ to $4 \%$ increases $\Phi_{\mathrm{L}}$ to 16.11 at $300^{\circ} \mathrm{C}$ and to 20.74 at $450^{\circ} \mathrm{C}$. 
The $\Phi_{L}$ increase as a function of HF incorporation can be attributed to the leaching of aluminum and silicon from the framework of the H-ZSM-5 zeolite followed by its deposition in the zeolitic channels along which diffusion takes place.

A plot of the activation energy (Fig. 9), Ea, and $\Phi_{\mathrm{L}}$ values shows an inversely proportional relationship; i.e. $E_{a}$ continually decreases with increasing the $\Phi_{\mathrm{L}}$ (and increase of HF), which is theoretically feasible, since diffusion limitation normally decreases the activation energy of the chemical reaction.

\section{CONCLUSION}

The catalysts investigated in this communication are originally H-ZSM-5 zeolite before and after treatment with 1.0, 2.0, 3.0 and $4.0 \% \mathrm{HF}$. Generally, the 2.0\%HF treated zeolite catalyst exhibited the highest activity (toluene conversion). All HF treated catalysts are more active than the untreated zeolite. The para-xylene selectivity increases with increasing the HF concentration up to $3.0 \%$, beyond which, the para-xylene selectivity declines with a further increase of acid concentration to $4.0 \%$. For comparison, at all reaction temperatures, the H-ZSM-5 $(3 \% \mathrm{HF})$ catalyst also gives the highest para-xylene selectivity. However, the H-ZSM-5 (4\%HF) catalyst at $450-500^{\circ} \mathrm{C}$, suffers from diffusion restriction effect caused by the debris formed via interaction of HF with aluminum and silicon in the zeolitic framework.

The Thiele modulus values calculated can be supportive for this assumption.

\section{REFERENCES}

[1] Vos, A. M., Rozanska, X., Schoonheydt, R.A., Santen, R.A.V., Hutschka, F., and Hafner, J. "A Theoretical Study of the Alkylation Reaction of Toluene with Methanol Catalyzed by Acidic Mordenite", J. Amer. Chem. Soc. 123, 2799-2809, (2001).

[2] Ratnasamy, P., Bhat, R.N., Pokhriyal, S.K., Hedge, S.G., and Kumar, R., "Reactions of aromatic hydrocarbons over zeolite $\beta$ ", J. Catal. 119, 65-70, (1989).

[3] Benito, I., Del Reigo, A., Martinez, M., Blanco, C., Pasquera, C., and Gonzalez, F., "Toluene methylation on $\mathrm{Al}_{13^{-}}$and $\mathrm{GaAl}_{12}$-pillared clay catalysts", Appl. catal. A 180, 175-182, (1999).

[4] Ghosh, A.K., and P. Harvey, "Toluene Methylation Process", US Patent 7060864B2, (2006).

[5] Wenstein, B., and N. J. Morganvill, "Selective Production of Para-Xylene", US Patent 3965207, (1976).

[6] Kodama, H., and Okazaki, S., "Alkylations of benzene, alkylbenzenes, and halobenzenes catalyzed by protonated mordenite pretreated with chlorofluorocarbons", J. Catal. 132, 512-523, (1991).

[7] Ding, C., Wang, X., Guo, X. and Zhang, S., "' Catal. Commun.s 9, 487-493, (2008).

[8] Zhu, Z., Chen, Q., Zhu, W., Kong, D. and and Li, C., "Catalytic performance of MCM-22 zeolite for alkylation of toluene with methanol" Catalysis Today 93-95, 321-325, (2004). 
[9] Zhu, Z., Chen, Q., Xie, Z., Yang, W. and Li, C., "The roles of acidity and structure of zeolite for catalyzing toluene alkylation with methanol to xylene", Microporus and Mesoporus Materials 88, 16-21, (2006).

[10] Li, Y.G., Xie, W.H., and Yong, S., "The acidity and catalytic behavior of Mg-ZSM5 prepared via a solid-state reaction", Appl. catal. A 150, 231-242, (1997).

[11] Faramawy, S., "Selective toluene-methanol alkylation over modified ZSM-5 zeolite catalysts", Pet. Sci. Technol 17, 249-271, (1999).

[12] Ghosh, A.K., and Kydd, R.A., "Fluorine-Promoted Catalysts", CataL Rev. ScL Eng. 27, 539-589, (1985).

[13] Lok, B.M., Goertsma, F.P., Messina, C.A., Rasteli, H., and Izod, T.P.J., ACS. Symp. Ser. 218, 41, Washington, DC, (1983).

[14] Becket, K.A., and Kowalak, S., "Catalytic properties of $\mathrm{H}$ mordenite modified with fluorine", J. Chem. Soc., Faraday Trans. 81, 1161-1166, (1985).

[15] Miale, J. N. , and Chang, C. D., "Activation of Zeolites", US Pat. (a) 4427786, (1984); (b) 4427787, (1984); (c) 4427788, (1984); (d) 4427789, (1984); (e) 4427790, (1984).

[16] Kokotailo, G. T., Rohrman, A. C. and Sawruk, S., US Pat. (a) "Modification of Catalytic Activity of Synthstic Zeolites", 4414189, (1983); and (b) "Modification of Catalytic Activity of Porus Zeolites", 4415544, (1983).

[17] Ghosh, A. K., and Kydd, R. A., "Acidity and activity of fluorinated mordenites", J. Catal. 103, 399-406, (1987).

[18] Aboul-Gheit, A.K., "Acid site strength distribution in mordenites by differential scanning calorimetry ", J. Catal. 113 490-496, (1988).

[19] Aboul-Gheit, A.K., " Effect of decantation and dealumination of zeolite $Y$ on its acidity as assessed by ammonia desorption measured by differential scanning calorimetry (DSC)", Thermochem. Acta 191, 233, (1991).

[20] Le Van Mao, R., Le, T.S., Fairbairn, M., Muntasar, A., Xiao, S., and Denes, G., "ZSM-5 zeolite with enhanced acidic properties", Appl. catal. A 185, 41-52, (1999).

[21] Taylor, W. J., Wagman, D. D., Williams, M. G., Pitzer, K. S., and Rossini, R. D., "' J. Res. Nat. Bur. 37, 95, (1946).

[22] Han, M., Xu, C., Lin, J., Liang, Y., and Roduer, E., "Alkylation of benzene with long-chain olefins catalyzed by fluorinated $\beta$ zeolite", Catalysis Letters Vol. 86, Nos. 1-3, 81-86, (2003).

[23] Satterfield, C. N. and Sherwood, T.K., "The Role of Diffusion in Catalysis", Addison-Sley, Reading, MA (1963). 
Table 1. Ammonia desorption enthalpy $(\Delta \mathrm{H})$ and peak temperature for untreated and hydrofluorinated $\mathrm{H}$-ZSM-5 catalysts

\begin{tabular}{|c|c|c|}
\hline \multirow{2}{*}{ Catalysts } & \multicolumn{2}{|c|}{ TPD of Ammonia } \\
\cline { 2 - 3 } & $\Delta \mathrm{H}, \mathrm{Jg}^{-1}$ & Peak Temp., ${ }^{\circ} \mathrm{C}$ \\
\hline Untreated H-ZSM-5 & 105.1 & 380.0 \\
\hline $\mathrm{H}-Z S M-5(1 \% \mathrm{HF})$ & 106.0 & 382.0 \\
\hline $\mathrm{H}-\mathrm{ZSM}-5(2 \% \mathrm{HF})$ & 107.5 & 385.0 \\
\hline $\mathrm{H}-\mathrm{ZSM}-5(3 \% \mathrm{HF})$ & 101.9 & 387.0 \\
\hline $\mathrm{H}-\mathrm{ZSM}-5(4 \% \mathrm{HF})$ & 98.3 & 388.0 \\
\hline
\end{tabular}

Table 2. Effect of HF concentration on surface area and pore volume of H-ZSM-5 zeolite

\begin{tabular}{|l|l|l|}
\hline Catalyst & BET surface area, $\mathrm{m}^{2} / \mathrm{g}$ & $\begin{array}{l}\text { Total pore volume, } \\
\mathrm{ml} / \mathrm{g}\end{array}$ \\
\hline Untreated H-ZSM-5 & 345.4 & 0.220 \\
\hline $\mathrm{H}-$ ZSM-5 (1\%HF) & 370.1 & 0.250 \\
\hline $\mathrm{H}-$ ZSM-5 (2\%HF) & 371.0 & 0.231 \\
\hline $\mathrm{H}-$ ZSM-5 (3\%HF) & 324.3 & 0.203 \\
\hline H-ZSM-5 (4\%HF) & 311.6 & 0.197 \\
\hline
\end{tabular}

Table 3. Activation parameters for the alkylation of toluene with methanol reaction using the current catalysts

\begin{tabular}{|c|c|c|}
\hline Catalyst & $\begin{array}{c}\mathrm{E}_{\mathrm{a}} \\
\text { Activation Energy } \\
\left(\times 10^{3} \mathrm{Jmol}^{-1}\right)\end{array}$ & $\begin{array}{c}\Delta \mathrm{S}^{*} \\
\text { Entropy } \\
\text { of Activation } \\
(\mathrm{eu})\end{array}$ \\
\hline $\mathrm{H}-\mathrm{ZSM}-5$ & 11.0 & -74.7 \\
\hline $1 \% \mathrm{HF} / \mathrm{H}-\mathrm{ZSM}-5$ & 27.1 & -68.0 \\
\hline $2 \% \mathrm{HF} / \mathrm{H}-\mathrm{ZSM}-5$ & 23.9 & -69.2 \\
\hline $3 \% \mathrm{HF} / \mathrm{H}-\mathrm{ZSM}-5$ & 19.8 & -70.8 \\
\hline $4 \% \mathrm{HF} / \mathrm{H}-\mathrm{ZSM}-5$ & 14.8 & -72.9 \\
\hline
\end{tabular}




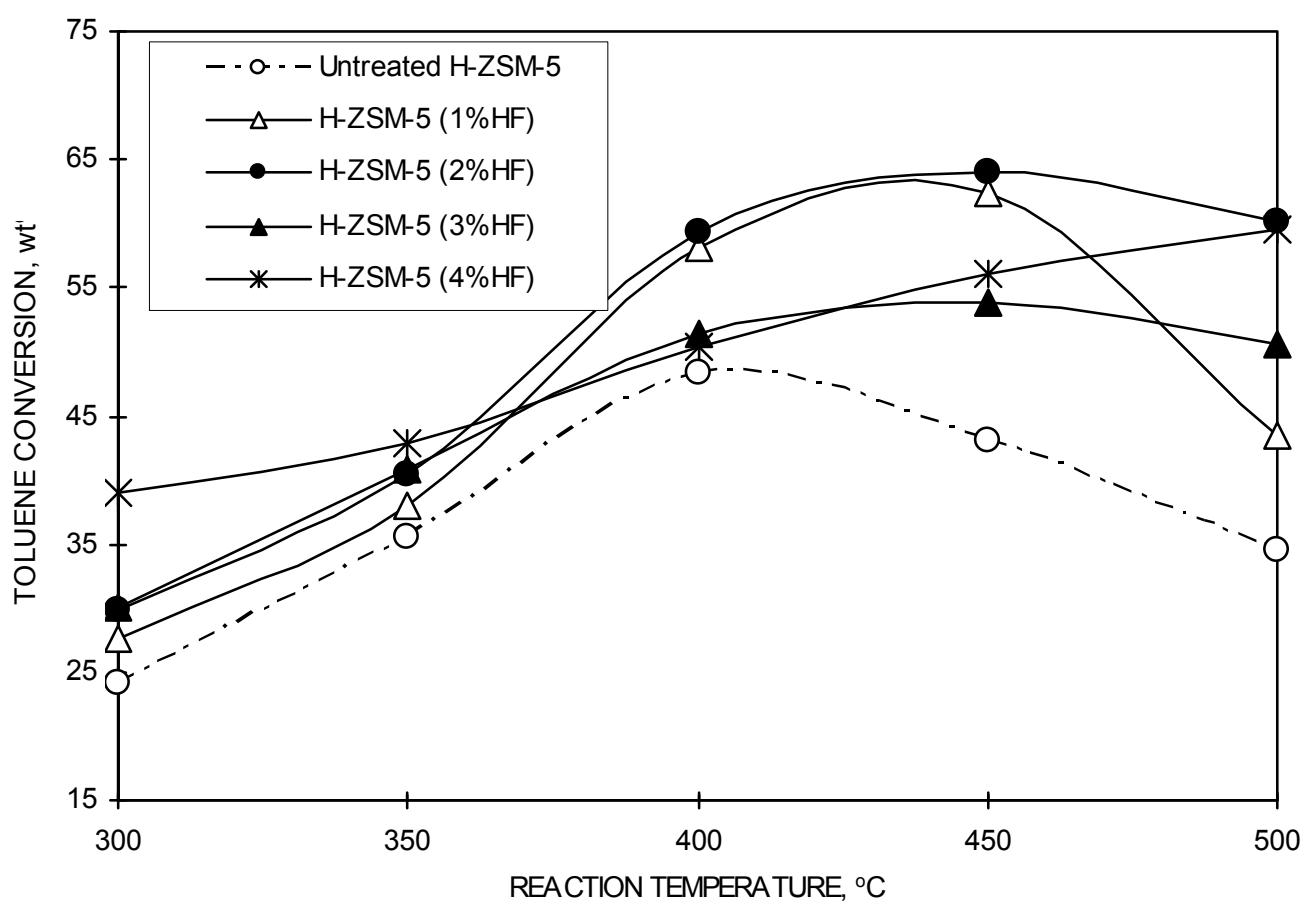

Fig. 1. Effect of reaction temperature on toluene conversion during toluene alkylation w ith methanol using untreated and fluorinated H-ZSM-5 catalysts.

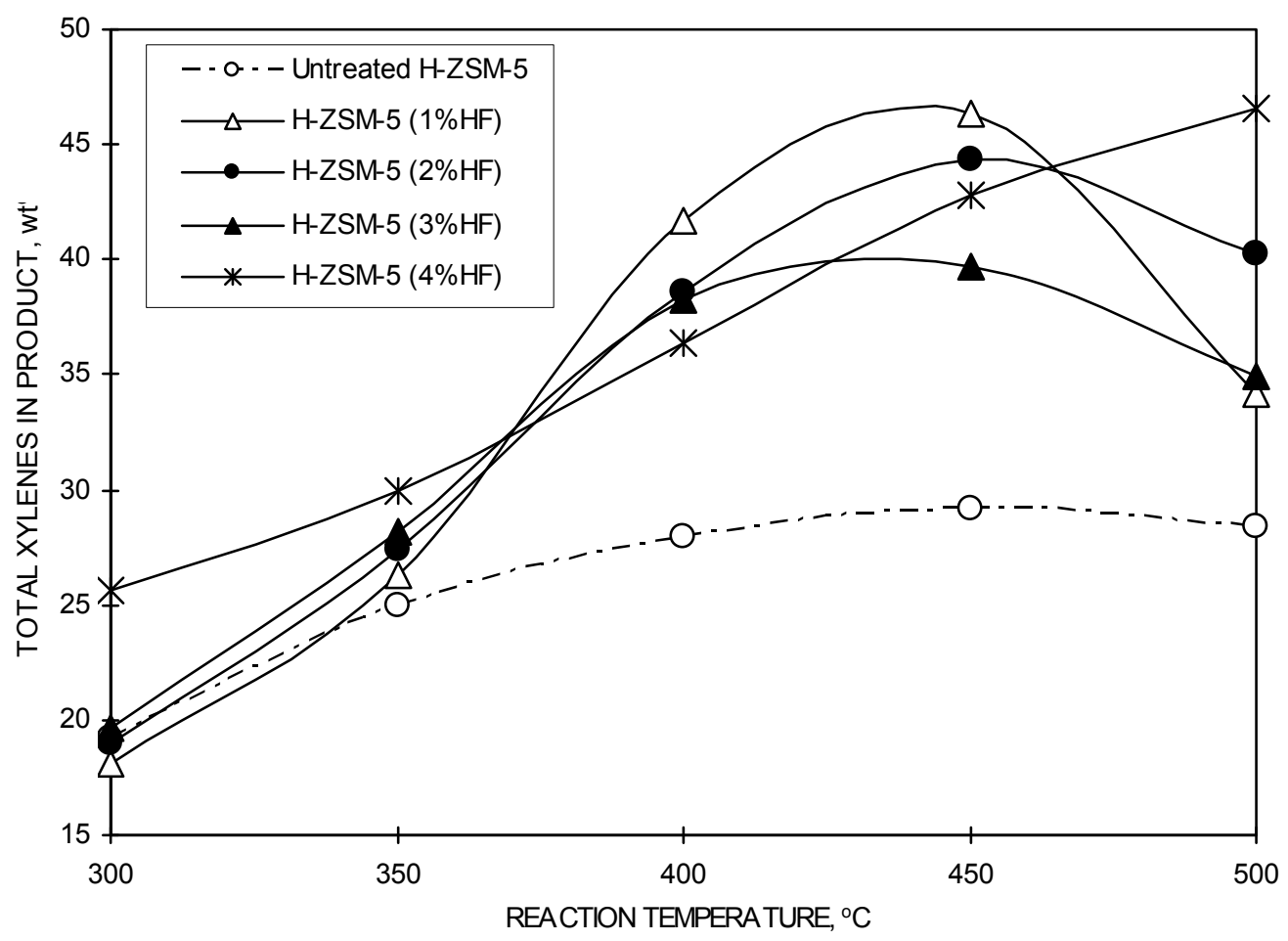

Fig. 2. Effect of reaction temperature on total xylenes in product for toluene alkylation w ith methanol using untreated and fluorinated $\mathrm{H}-\mathrm{ZSM}-5$ catalysts. 


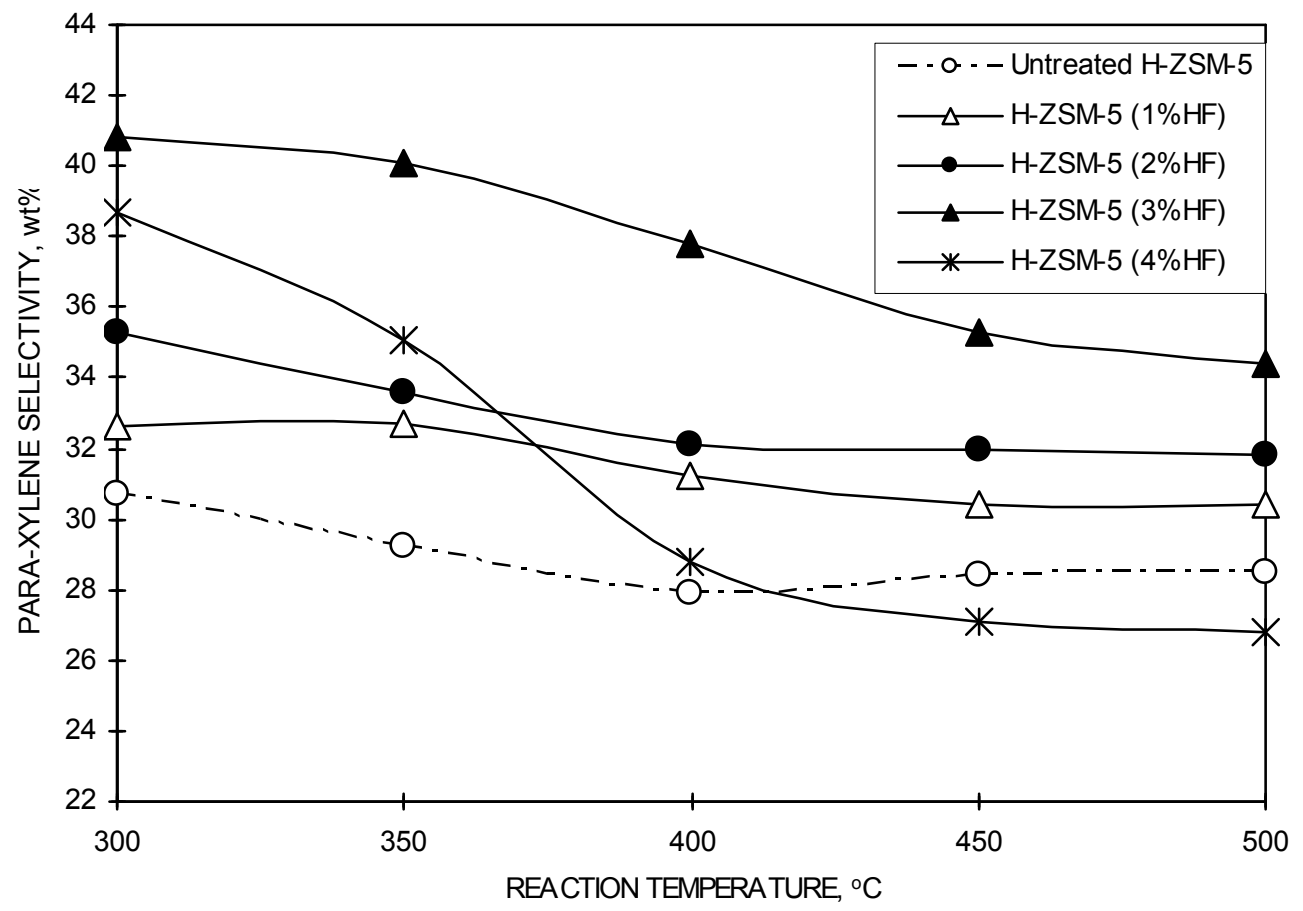

Fig. 3. Effect of reaction temperature on para-xylene selectivity for toluene alkylation w ith methanol using untreated and fluorinated H-ZSM-5 catalysts.

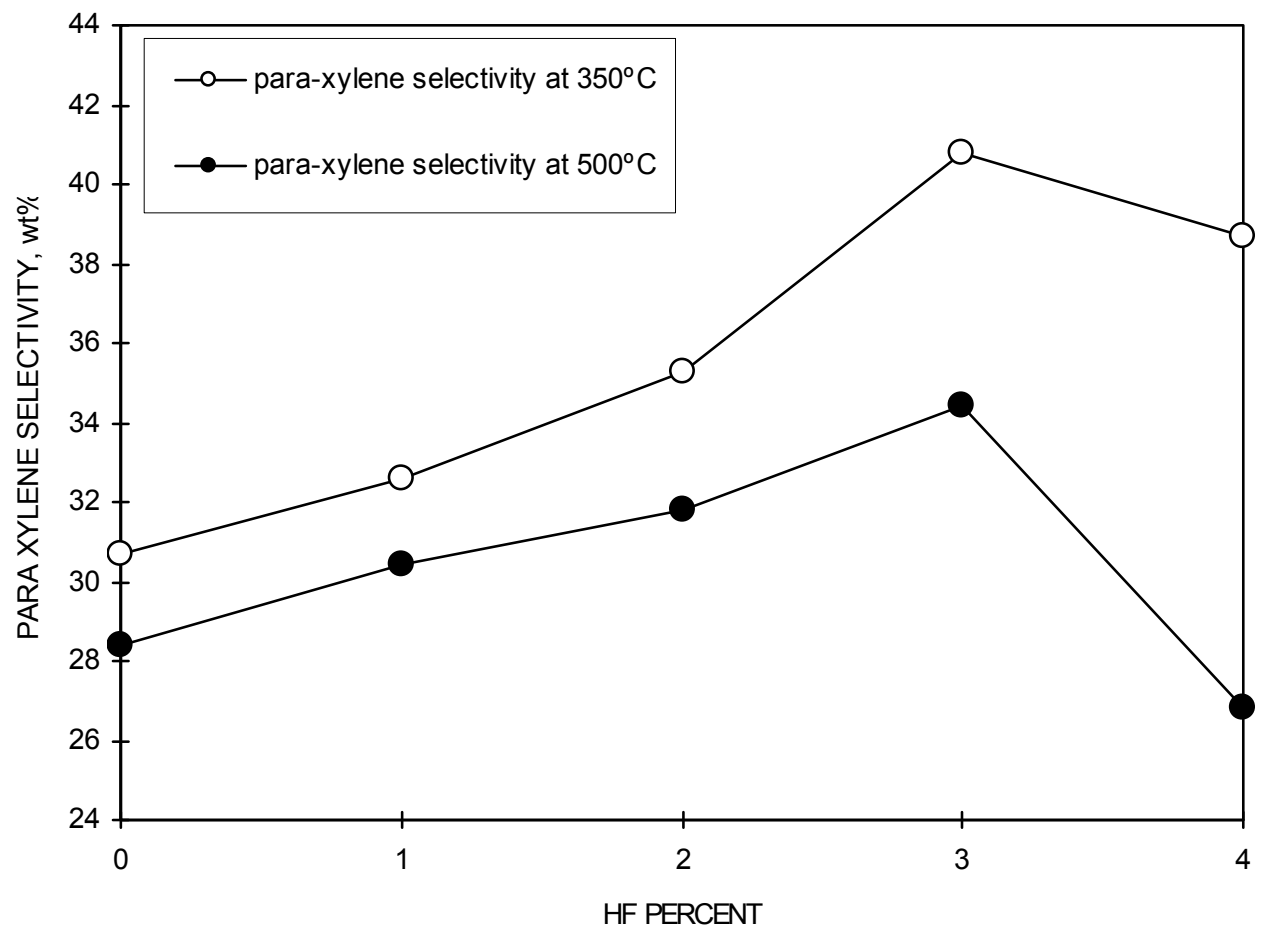

Fig. 4. Effect of $\mathrm{HF}$ addition in $\mathrm{H}-\mathrm{ZSM}-5$ zeolite catalyst on para xylene selctivity at $300^{\circ} \mathrm{C}$ and $500^{\circ} \mathrm{C}$ 


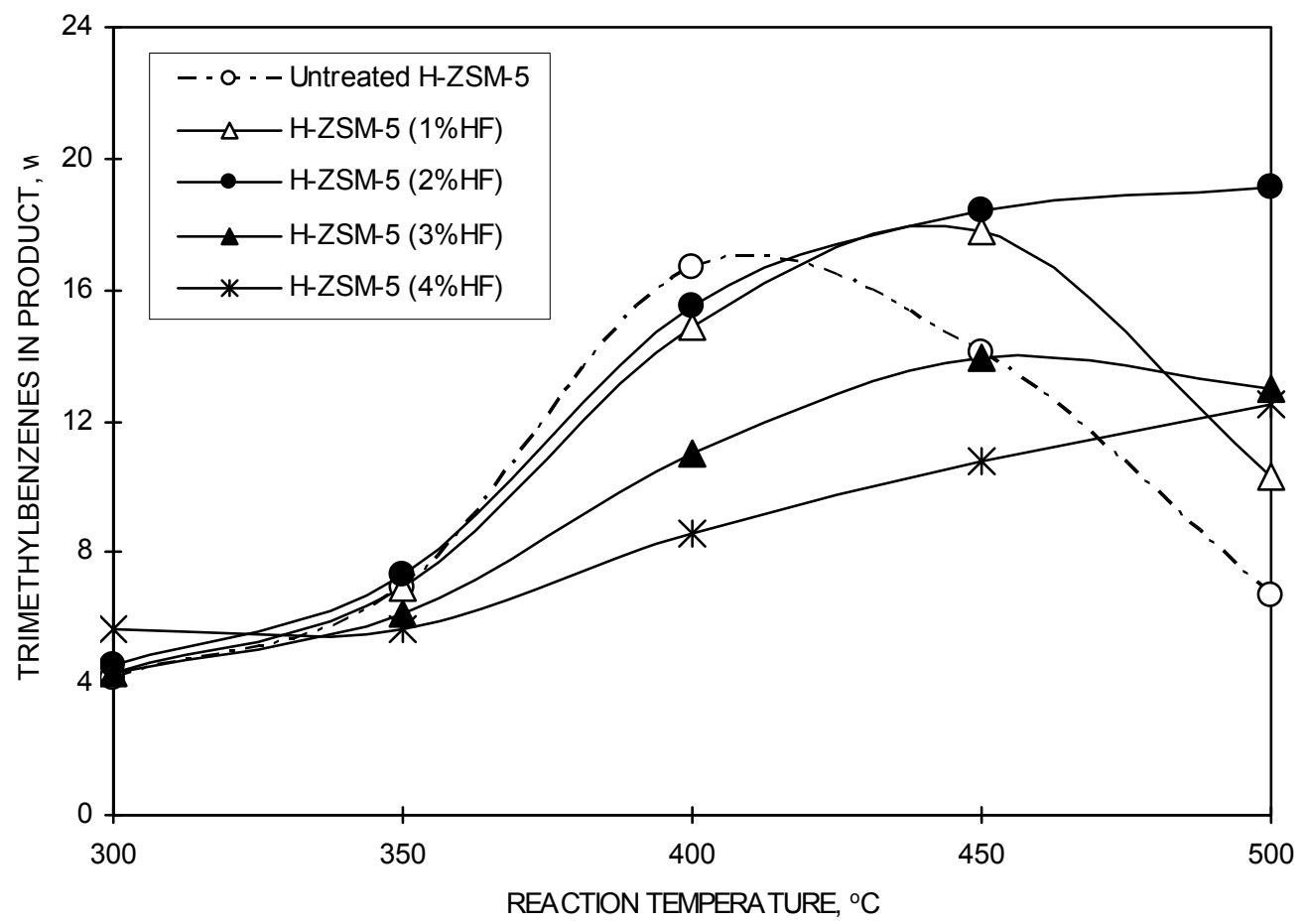

Fig. 5. Effect of reaction temperature on trimethylbenzenes in product for toluene alkylation w ith methanol using untreated and fluorinated $\mathrm{H}-\mathrm{ZSM}-5$ catalysts.

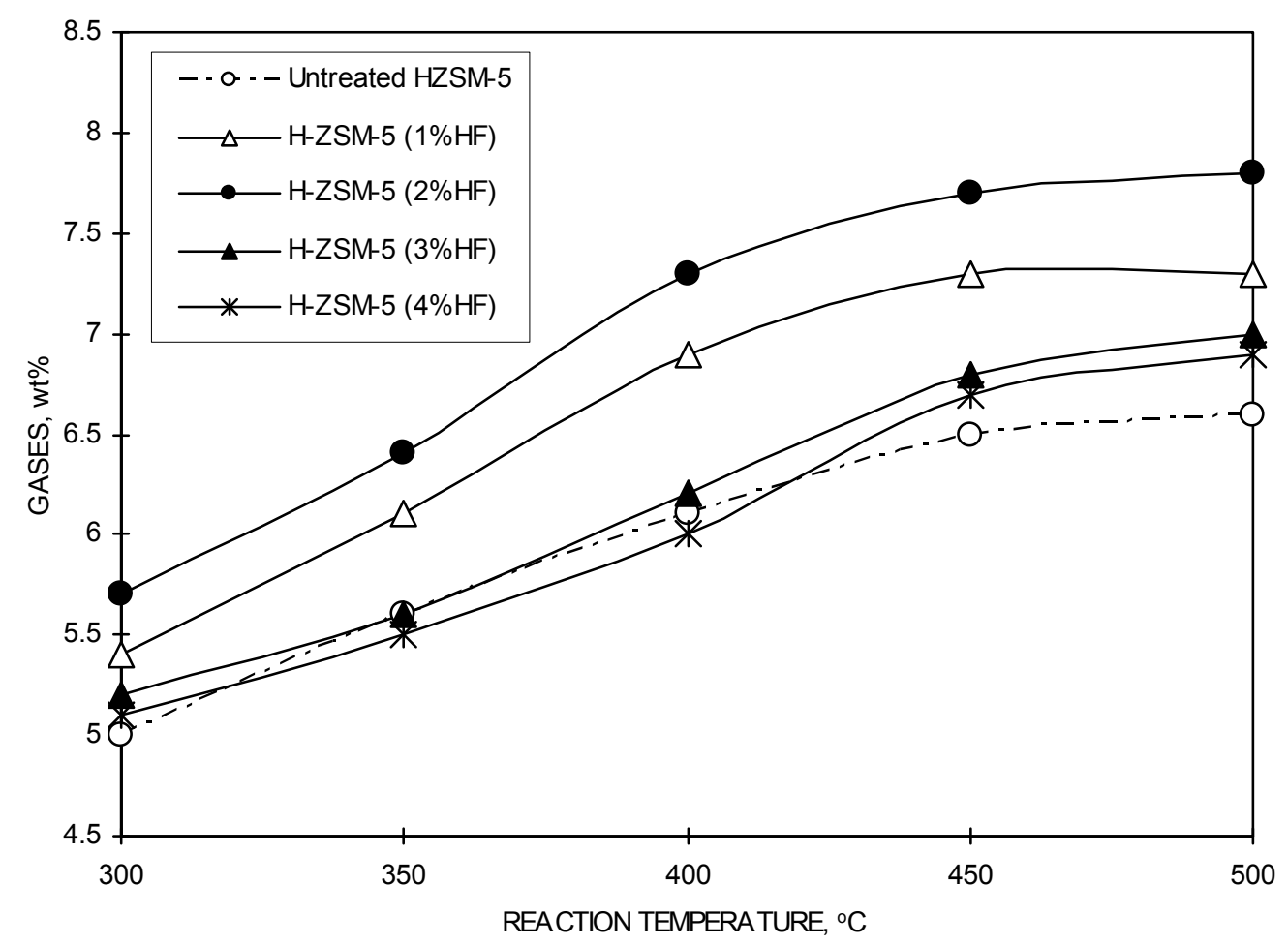

Fig. 6. Total gases produced during toluene alkylation $w$ ith methanol using untreated and fluorinated $\mathrm{H}$-ZSM-5 catalysts. 


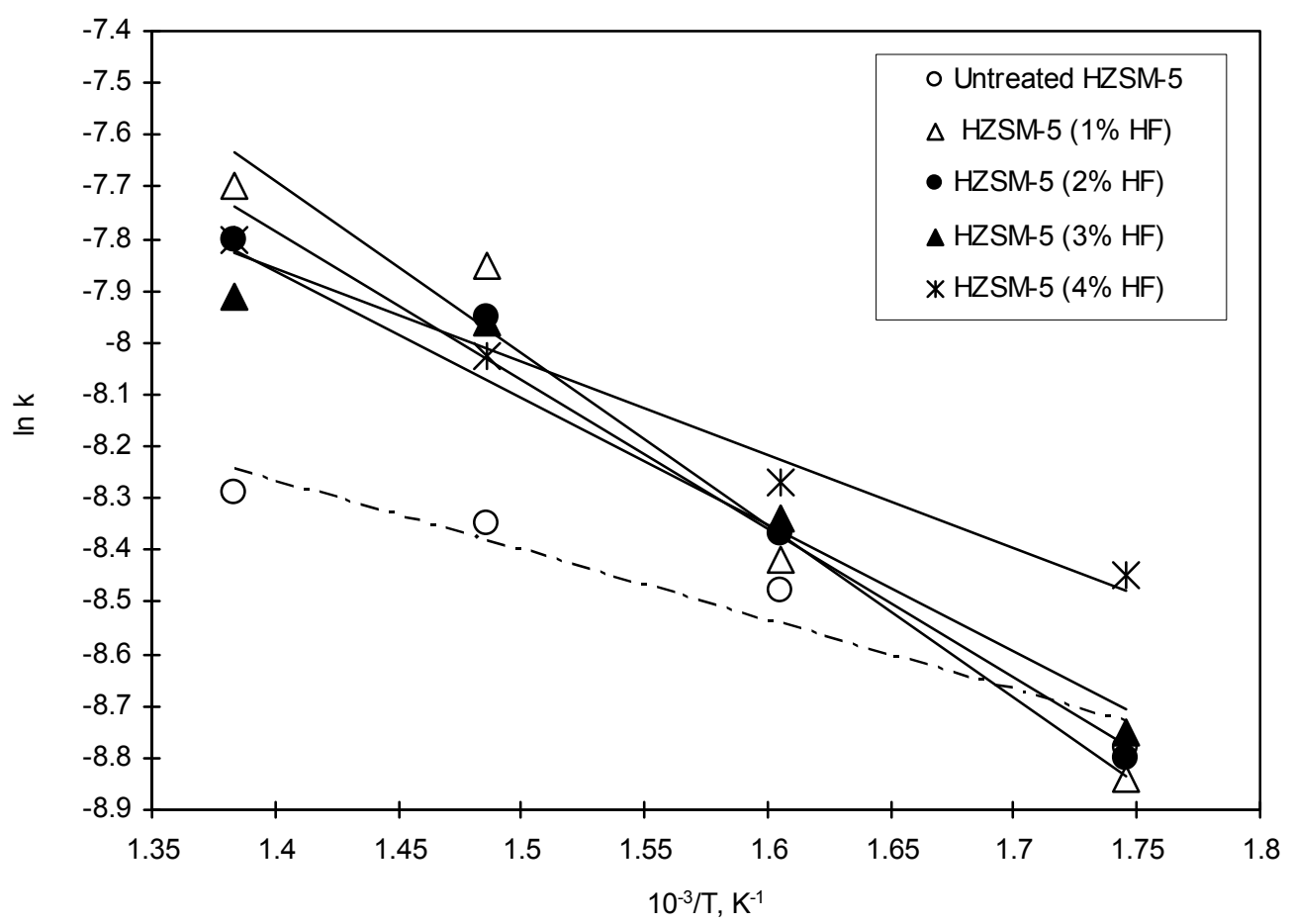

Fig. 7. Arrhenius plot for alkylation of toluene $w$ ith methanol reaction using the fluorinated H-ZSM-5 catalysts.

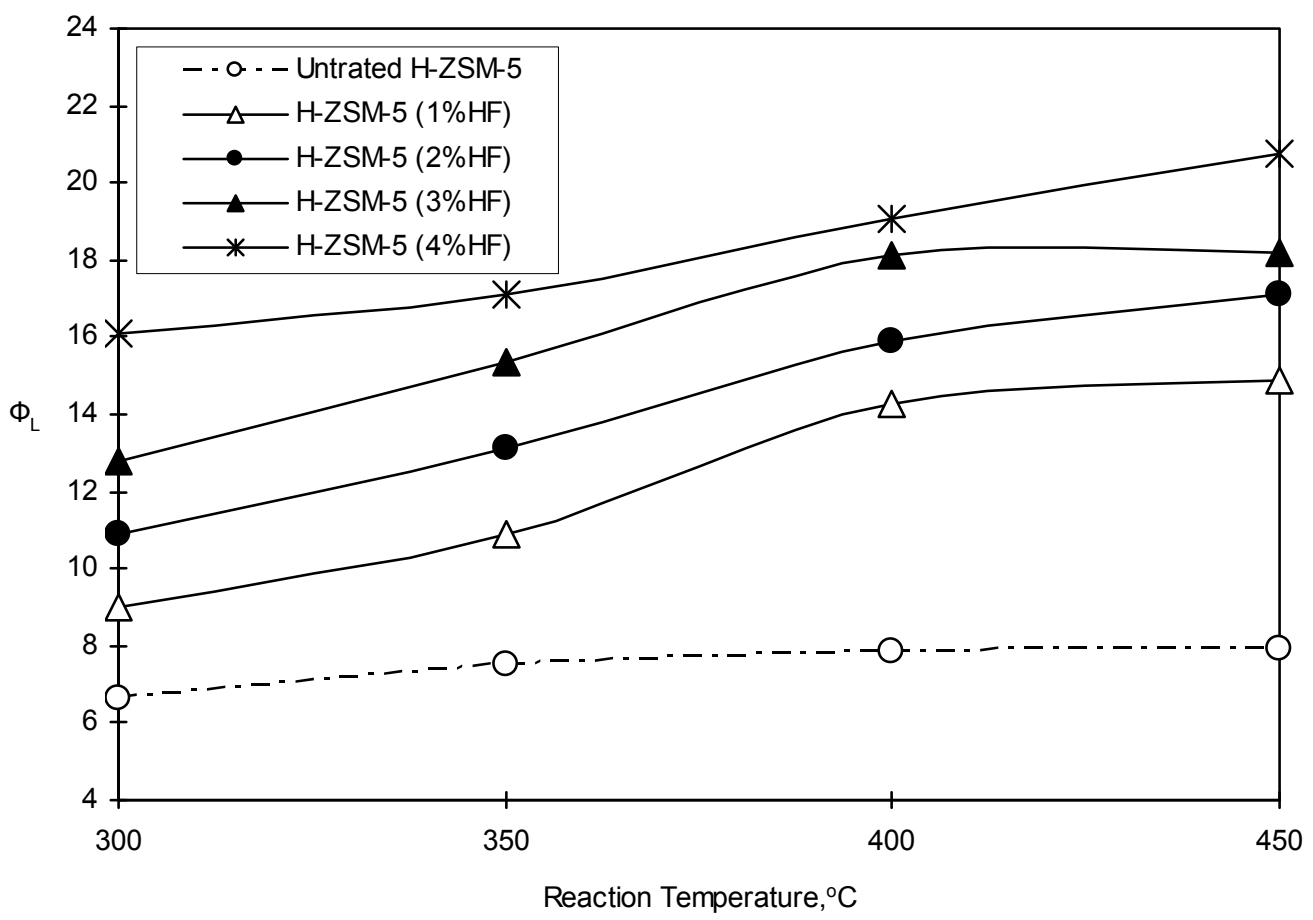

Fig. 8. Thiele modulus $\left(\Phi_{L}\right)$ for the methylation of toluene with methanol using using H-ZSM-5 zeolite before and after treatment $w$ ith different HF concentrations. 
Proceeding of the $4^{\text {th }}$ ICEE Conference 27-29 May 2008

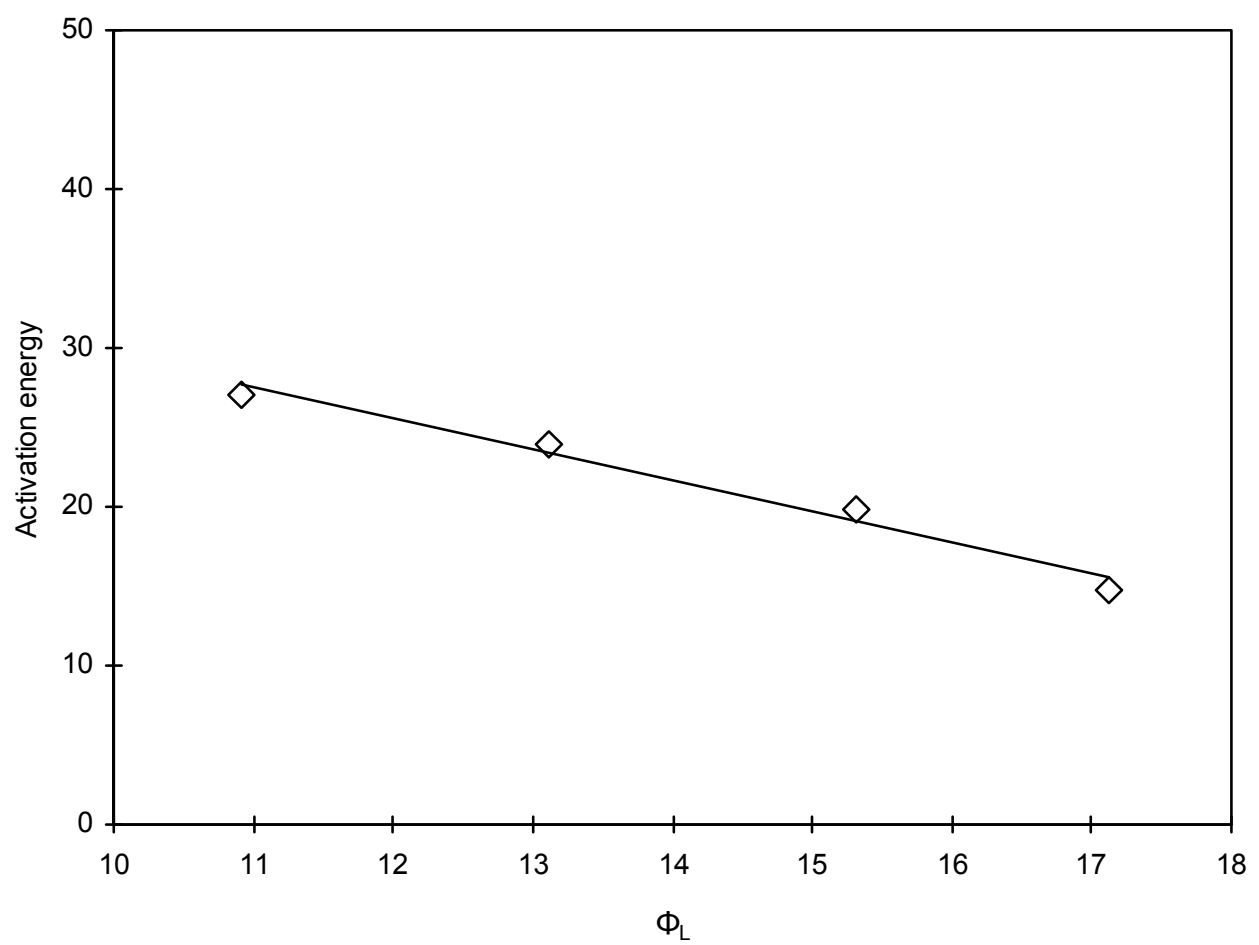

Fig. 9. Activation energy for toluene alkylation with methanol vs. $\Phi_{L}$ at $350^{\circ} \mathrm{C}$ as a function of HF doping in the catalyst. 